\title{
Management of refractory Pseudomonas aeruginosa infection in cystic fibrosis
}

\author{
This article was published in the following Dove Press journal: \\ Infection and Drug Resistance \\ 24 January 2011 \\ Number of times this article has been viewed
}

Roger Sordél,2

Albert Pahissa ${ }^{1,2}$

Jordi Rello 3,4

'Department of Infectious Diseases, Hospital Universitari Vall d'Hebron,

Vall d'Hebron Research Institute (VHIR), Universitat Autònoma de Barcelona, Barcelona, Spain; ${ }^{2}$ Spanish Network for Research in Infectious Diseases (REIPI), Spain; ${ }^{3}$ Department of Critical Care, Hospital Universitari Vall d'Hebron, Vall d'Hebron Research Institute (VHIR), Universitat Autònoma de Barcelona, Barcelona, Spain; ${ }^{4}$ CIBER Enfermedades Respiratorias (CIBERES), Spain
Correspondence: Roger Sordé Masip Department of Infectious Diseases, Hospital Universitari Vall d'Hebron, Vall d'Hebron Research Institute (VHIR), Universitat Autònoma de Barcelona, $P^{\circ}$ Vall d'Hebron I 19-129, 08035

Barcelona, Spain

Tel +34932746090

Fax +34934894091

Email rsorde@ir.vhebron.net

\begin{abstract}
Cystic fibrosis (CF) is the most common life-limiting inherited disease in Caucasian populations. The main cause of death in $\mathrm{CF}$ patients is respiratory failure resulting from chronic pulmonary infection. Pseudomonas aeruginosa is the most prevalent organism in the airway colonization of CF patients, and its persistence in the airways has been related to greater morbidity with a more rapid deterioration in lung function. P. aeruginosa has enormous genetic and metabolic flexibility that allows it to adapt and persist within the airways of CF patients, and it has the ability to easily acquire antimicrobial resistance. For these reasons, the management of infections and chronic colonization by $P$. aeruginosa remains a challenge for physicians. This article reviews the current and future antibacterial chemotherapy options for respiratory pseudomonal infection in $\mathrm{CF}$ patients.
\end{abstract}

Keywords: cystic fibrosis, Pseudomonas aeruginosa, respiratory infection, antimicrobial treatment

\section{Introduction}

Cystic fibrosis (CF) is a multisystem disorder caused by mutations on the cystic transmembrane conductance regulator (CFTR) gene located on chromosome $7 .{ }^{1}$ It is the most common life-limiting, autosomal recessively inherited disease in Caucasian populations. Although this is a multisystem disorder, pulmonary disease remains the leading cause of morbidity and mortality in patients with CF. The primary cause of death in these patients is respiratory failure resulting from chronic pulmonary infection. ${ }^{2}$ Early infections in CF airways are most frequently caused by Staphylococcus aureus and Haemophilus influenzae, organisms that may be seen in other young children with chronic illnesses and in adults with non-CF bronchiectasis. Other organisms that are identified later in the course of CF airways disease include Burkholderia cepacia, Stenotrophomonas maltophilia, Achromobacter xylosoxidans, fungi including Aspergillus, and nontuberculous mycobacteria. Nevertheless, CF airway is particularly susceptible to Pseudomonas aeruginosa, which is considered the most important pathogen in this chronic disease. The prevalence of $P$. aeruginosa infection increases as patients age, such that $>70 \%$ of adults are chronically infected. ${ }^{3}$ P. aeruginosa is extremely difficult to eradicate once established in the CF airway. This phenomenon is due to poor penetration of antibiotics into purulent airway secretions, native or acquired antibiotic resistance, CF-related defects in mucosal defenses, or biofilms produced by the bacteria, which interfere with phagocytic killing. Although chronic infection has been referred as 'airway colonization', the presence of these bacteria is not benign. Epidemiologic studies show that chronic infection with $P$. aeruginosa is 
an independent risk factor for accelerated loss of pulmonary function and decreased survival. ${ }^{4,5}$

The quality of life and life expectancy of CF patients have improved considerably as a result of the control of bronchopulmonary bacterial colonization and exacerbations. ${ }^{6}$ Nevertheless, because of the lack of scientific evidence, these issues remain a challenge for physicians.

This article reviews the current and future antibacterial chemotherapy options for respiratory pseudomonal infection in CF patients.

\section{Epidemiology and pathogenesis of $P$. aeruginosa}

P. aeruginosa is a usually noncapsulate, nonsporing, and nonfermenting Gram-negative bacillus that is common in the environment, especially in water. The ability of $P$. aeruginos $a$ to persist and multiply in moist environments (soil detritus and equipment such as humidifiers in hospital wards, urinary catheters, bathroom sinks, and kitchens) is of particular importance in crossinfection. ${ }^{7}$

Currently, $P$. aeruginos $a$ is a pathogen of great relevance in infectious disease for different reasons: $a$ ) reservoirs for infection can develop, especially in intensive care units, often associated with water in sinks or respiratory equipment; b) the microorganism displays a predilection for infecting immunocompromised hosts (including burn patients) whose proportion is increasing in our hospitals and society; $c$ ) it is the most serious pathogen in ventilator-associated pneumonia and one of the most common in other nosocomial infections; and $d$ ) there is an increase in occurrence of $P$. aeruginosa strains with resistance to multiple antibiotics. ${ }^{8}$

P. aeruginosa is the most common cause of respiratory failure in $\mathrm{CF}$ and is responsible for the death of the majority of these patients. Acquisition of P. aeruginosa begins early in childhood. ${ }^{9}$

It is believed that the bacterium is initially acquired from environmental sources, but patient-to-patient spread has also been described. ${ }^{10,11}$ In patients with CF, prevalence of pseudomonal pneumonia ranges from $21 \%$ in those younger than 1 year to $>80 \%$ in those older than 19 years. The increasing longevity of patients with CF has created a significant shift in the proportion of adult patients with CF; their proportion has increased fourfold, from $8 \%$ in 1969 to $33 \%$ in $1990 .{ }^{12}$

Impaired mucociliary clearance and bronchiectatic changes to the airways predispose patients with $\mathrm{CF}$ to lower respiratory tract bacterial colonization and recurrent infections, especially by $P$. aeruginosa.$^{13}$ P. aeruginosa has enormous genetic and metabolic flexibility that allows it to adapt to the milieu and persist within the airways of CF patients. The genotypes and phenotypes of the strains present in late stages of the disease differ substantially from those that initially colonize the lungs. ${ }^{14}$ Initial isolates of this microorganism are often nonmucoid strains. As lung disease progresses, mutants with a mucoid phenotype owing to alginate overexpression are selected. Exopolysaccharide production is increased in response to the hypoxic environment of the mucus that covers the airway surface and contributes to highly structured biofilm formation. ${ }^{15}$ Alginate protects $P$. aeruginosa from being killed by immune cells because it provides a physical barrier for the bacteria and it scavenges free radicals released by neutrophils and macrophages. ${ }^{16}$ These mucoid strains are associated with deterioration in cough scores, chest X-ray scores, and pulmonary function. ${ }^{17}$ Deterioration in lung function is related to anatomical changes in the airways caused by enhanced and persistent inflammation. Patients with CF have an increased number of neutrophils and levels of IL-8 in bronchoalveolar lavage (BAL) fluid and reduced production of IL-10, an anti-inflammatory cytokine, as compared with non-CF patients. Accordingly, they have an abnormally intense and prolonged inflammatory response to infections and the products of this excessive inflammation, which include neutrophil elastase and DNA fragments from apoptotic neutrophils, contribute to anatomic damage. ${ }^{6}$

The genetic and metabolic flexibility of $P$ aeruginosa also contributes to its ability to develop antimicrobial resistance, making eradication of $P$. aeruginosa infection almost impossible. One of the major mechanisms of resistance to many antibiotics is the expression of multiple efflux pump systems. ${ }^{18,19}$ In addition, $P$. aeruginosa has the ability to acquire antimicrobial resistance genes encoded in plasmids and transposons through horizontal transfer from other Gram-negative bacteria. ${ }^{20}$

\section{Clinical assessment of pulmonary health status}

Routine imaging and laboratory evaluations are critical to assessing pulmonary status in CF patients. These studies are used to monitor disease progression and response to therapeutic interventions and evaluate exacerbations.

Chest X-rays are helpful for defining disease progression (detection of hyperinflation with flattened diaphragms, retrosternal lucency, nodular opacities due to mucus plugging, and cystic changes due to bronchiectasis). Chest X-ray scores 
have been developed for assessing disease progression, ${ }^{21,22}$ but have never been used widely in clinical practice. ${ }^{6}$

High-resolution computerized tomography (HRCT) is more sensitive and specific than chest radiographs in identifying changes in early CF lung disease (airway wall thickening, gas trapping) and is particularly useful in identifying localized areas of bronchiectasis and parenchymal abnormalities. ${ }^{23}$ Accordingly, HRCT is being used to document localized disease and respond to antibiotic therapy during acute exacerbations. ${ }^{24}$ The cost and radiation exposure are some of the reasons that explain the lack of consensus guidelines for use of HRCT in CF care. ${ }^{25}$

The main measure of pulmonary status in individuals with $\mathrm{CF}$ is pulmonary function testing with spirometry or plethysmography. Lung function measurements are useful in documenting stability or progression of airway obstruction and air trapping. These tests are also useful to detect acute changes associated with pulmonary exacerbations and response to therapy. ${ }^{6}$ The earliest spirometric evidence of obstructive disease is a decrease in expiratory flows at low volumes such as forced expiratory flow between $25 \%$ and $75 \%$, while the most widely used parameter to evaluate lung status is forced expiratory volume in 1 second $\left(\mathrm{FEV}_{1}\right)$ because of the universal accessibility of spirometric equipment, standardized criteria for performance, availability of reference values, and reproducibility. ${ }^{26,27}$

In daily practice, $\mathrm{FEV}_{1}$ has two important functions: 1) it is the primary marker for disease progression identified in numerous epidemiologic studies to predict decline in health status and mortality ${ }^{28}$ and 2) it is the primary outcome measure used for defining clinical efficacy for therapeutic modalities in $\mathrm{CF}^{29}$

\section{Microbiological assessment of $P$. aeruginosa}

Microbiological studies are mostly performed using sputum samples. However, collecting this specimen may be difficult in the younger patients. Oropharyngeal cultures have been well studied in this situation but their value is inferior to that of sputum because of their lower sensitivity. ${ }^{30}$

$\mathrm{BAL}$ is a more sensitive measure for diagnosing infection, and it is also more invasive. This test should be reserved for assessing patients unresponsive to antimicrobial therapy or those with progressive disease. ${ }^{31}$ Hypertonic saline induction of sputum has been reported to be a good surrogate for lower airway sampling in both adult and older pediatric patients with $\mathrm{CF}^{32}$
In patients with an early diagnosis of $\mathrm{CF}$, it is essential to undertake continuous microbiological monitoring to detect incipient colonization by $P$. aeruginosa. In this stage, optimal frequency for performing sputum cultures is controversial. A monthly, or at least trimonthly, culture is advisable for patients without evidence of $P$. aeruginosa colonization in order to detect the initial isolation and initiate early treatment. From other patients, cultures should be taken whenever exacerbations present or, at least, every $2-3$ months in periods with clinical stability. ${ }^{33,34}$

All $P$. aeruginosa morphotypes isolated in the culture should be tested for susceptibility to antimicrobial agents. There is consensus that incubation of susceptibility tests should be for at least $24 \mathrm{~h}$ to facilitate growth of mucoid and small-colony variants. The precise method to evaluate this issue remains controversial but it should permit calculation of the MIC. ${ }^{35,36}$

\section{Interaction patterns of $P$. aeruginosa with lungs: colonization versus infection}

'Colonization' refers to bacterial development on a surface without harmful effects while 'infection' indicates a pathogenic effect resulting from microbial invasion of the tissues. ${ }^{5}$

In CF patients, pulmonary infections are associated with symptoms and clinical signs of respiratory illness: increased cough, increased sputum production, decreased exercise tolerance or increased dyspnea with exertion, increased fatigue, decreased appetite, increased respiratory rate or dyspnea at rest, change in sputum appearance, fever, and increased nasal congestion or drainage. These clinical situations tend to correspond to clinical respiratory exacerbations of a chronic bacterial colonization. ${ }^{37}$

Classically, in CF patients the term 'colonization' has been used to describe a clinical situation without symptoms or signs consistent with pulmonary infection but with persistence of the same microorganisms in successive sputum cultures. In case of $P$. aeruginosa, its persistence in the airways has been related to greater morbidity with a more rapid deterioration in lung function. ${ }^{4}$ For this reason, it could be more accurate to refer to this situation in terms of 'pathogenic colonization' or 'chronic infection'. ${ }^{34}$

Different microbiological patterns and criteria in pulmonary $P$. aeruginosa colonization/infection in CF patients are summarized in Table 1. This classification is clinically important because each situation should be addressed differentially from the therapeutic viewpoint. 
Table I Microbiological patterns and criteria in pulmonary Pseudomonas aeruginosa colonization/infection in cystic fibrosis patients

\begin{tabular}{|c|c|c|c|}
\hline Infection/colonization & Definition & Microbiological criteria & Comments \\
\hline $\begin{array}{l}\text { I. Initial colonization } \\
\text { (first colonization event } \\
\text { or pioneer colonization) }\end{array}$ & $\begin{array}{l}\text { Detection of the first positive } \\
P \text {. aeruginosa culture in the } \\
\text { bronchial tree. No clinical } \\
\text { symptoms }\end{array}$ & First positive $P$. aeruginosa culture & $\begin{array}{l}\text { A positive culture following } \\
\text { I year of negative cultures after } \\
\text { finishing treatment is considered } \\
\text { as a new initial colonization. } \\
\text { The strains are usually nonmucoid } \\
\text { colonies, with little diversity in } \\
\text { morphotypes or antimicrobial } \\
\text { susceptibilities }\end{array}$ \\
\hline $\begin{array}{l}\text { II. Sporadic or } \\
\text { intermittent colonization }\end{array}$ & $\begin{array}{l}\text { Intermittent presence of positive } \\
\text { and negative } P \text {. aeruginosa } \\
\text { cultures in consecutive samples } \\
\text { after initial colonization. } \\
\text { No signs of infection }\end{array}$ & $\begin{array}{l}\text { Detection, within a period of } 6 \text { months } \\
\text { of the initial colonization, of a positive } \\
P . \text { aeruginosa culture among at least } \\
\text { three cultures, with at least I month } \\
\text { between each positive culture }\end{array}$ & $\begin{array}{l}\text { Possible recovery of strains } \\
\text { with mucoid colonies and other } \\
\text { colonial morphotypes }\end{array}$ \\
\hline $\begin{array}{l}\text { III. Colonization with } \\
\text { bronchopulmonary } \\
\text { infection }\end{array}$ & $\begin{array}{l}\text { Initial or sporadic } \\
\text { colonization with } \\
\text { presentation of clinical signs } \\
\text { of infection }\end{array}$ & As for initial or sporadic colonization & $\begin{array}{l}\text { In patients without } \\
\text { microbiological specimens, the } \\
\text { appearance or increase of } \\
\text { antibodies in two successive } \\
\text { blood samples, with at least } \\
3 \text { months between each sample, } \\
\text { can be used as a diagnostic } \\
\text { criterion }\end{array}$ \\
\hline IV. Chronic colonization & $\begin{array}{l}\text { Persistent positive } P \text {. aeruginosa } \\
\text { cultures without new clinical } \\
\text { signs of infection }\end{array}$ & $\begin{array}{l}\text { Detection within a period of } 6 \text { months } \\
\text { of a minimum of three positive } \\
P . \text { aeruginosa cultures, with at least } \\
\text { I month between the positive cultures }\end{array}$ & $\begin{array}{l}\text { Usually produced by strains } \\
\text { with mucoid colonies and other } \\
\text { colonial morphotypes. This is } \\
\text { the common pattern during } \\
\text { advanced periods of the disease }\end{array}$ \\
\hline $\begin{array}{l}\text { V. Chronic } \\
\text { bronchopulmonary } \\
\text { infection (exacerbation) }\end{array}$ & $\begin{array}{l}\text { Presentation of clinical signs } \\
\text { of infection during the course } \\
\text { of a chronic colonization }\end{array}$ & As for chronic colonization & $\begin{array}{l}\text { In patients with microbiological } \\
\text { specimens, an increase of } \\
\text { antibodies in two successive } \\
\text { blood samples can be used as a } \\
\text { diagnostic criterion }\end{array}$ \\
\hline
\end{tabular}

Copyright $@$ 2005, Wiley. Adapted with permission from Cantón R, Cobos N, de Gracia J, et al. Antimicrobial therapy for pulmonary pathogenic colonisation and infection by Pseudomonas aeruginosa in cystic fibrosis patients. Clin Microbiol Infect. 2005; I I (9):690-703.

\section{Antimicrobial treatment in clinical practice \\ Special issues in CF pharmacokinetics}

CF patients generally have a larger volume of distribution $\left(V_{\mathrm{d}}\right)$ for many antibiotics, including $\beta$-lactam agents and aminoglycosides, due to their lower fat stores and an increased ratio of lean body mass to total body mass compared with the non-CF population. Consequently, larger doses of antibacterial agents must be given to attain the same serum concentration as individuals with a larger adipose mass. ${ }^{38,39}$ Enhanced total body clearance of antibiotics has also been observed within the CF population. Increased renal clearance, decreased protein binding, extrarenal elimination, and increased metabolism have been proposed as possible reasons for this increased clearance although the exact mechanism has not been determined. There are fewer pharmacokinetic deviations for fluoroquinolones; however, higher doses are typically needed for activity against CF pathogens. ${ }^{38}$
The increased $V_{\mathrm{d}}$ and enhanced clearance of antibiotics, combined with the difficulty of lung tissue penetration and P. aeruginosa antimicrobial resistance, make antibiotic dosing to get therapeutic drug concentrations a real challenge in $\mathrm{CF}$ patients. Aminoglycosides have been widely studied trying to optimize their therapeutic concentrations and minimize toxicity. The bactericidal efficacy of this antibiotic family is peak dependent (postdose drug concentration) while the main adverse effects such as nephrotoxicity are trough dependent (predose drug concentration). ${ }^{40}$ Historically, aminoglycosides have been administered three times daily in CF patients with normal renal function; however, recent strategies have included once-daily dosing regimens in an effort to maximize peak and minimize trough concentrations. ${ }^{41,42} \mathrm{~A}$ meta-analysis published in 2010 concluded that once and three times daily aminoglycoside antibiotics appear to be equally effective in the treatment of pulmonary exacerbations of CF patients with evidence of less nephrotoxicity in children in the once-daily regimen. ${ }^{43}$ 
Commonly used antimicrobial agents for $P$. aeruginosa infections are shown in Table 2.

\section{Eradication strategies to prevent chronic $P$. aeruginosa infection}

Active treatment of first isolation of $P$. aeruginosa is critical in order to delay or prevent chronic infection state and its clinical consequences. ${ }^{44}{ }^{47}$ The authors of a recent meta-analysis ${ }^{48}$ conclude that treating of early infection results in microbiological eradication of $P$. aeruginosa for several months. There is insufficient evidence to state which antibiotics strategy should be used for the eradication of early P. aeruginosa infection because of the enormous heterogeneity in regimens administered by clinicians from different $\mathrm{CF}$ specialized centers. ${ }^{45,49,50}$ These regimens most often include the combination of oral fluoroquinolones and/or intravenous antipseudomonal agents with a prolonged course of inhaled tobramycin or colistin. In our setting, stable patients (without respiratory symptoms) usually receive oral ciprofloxacin (30-40 mg/kg/day) divided into two doses (maximum $2 \mathrm{~g} /$ day) for 3-4 weeks combined with inhaled tobramycin or colistin. If sputum culture is negative 1 month after the start of treatment, the inhaled therapy is maintained for at least 6 months to avoid early recurrence; whereas, if culture is positive, the treatment cycle is repeated. If the sputum collected at the end of the second cycle is still positive, the patient is considered chronically colonized. ${ }^{34}$ For positive $P$. aeruginosa cultures, an antibiogram should be performed and the antimicrobial therapy should be adapted accordingly. Despite the high prevalence of susceptibility to antipseudomonal antibiotics found in P. aeruginosa associated with initial infections, an antibiogram should also be performed in this situation because susceptibility in early isolates cannot be presumed. ${ }^{51}$ The US multicenter Early Pseudomonas Infection Control (EPIC) study is currently in process. This investigation is evaluating different strategies for early $P$. aeruginosa eradication and observing the natural history of its acquisition in early childhood.

\section{Maintenance after development of chronic $P$. aeruginosa infection}

Both oral and inhaled antibiotics offer potential benefits to patients with chronic respiratory P. aeruginosa infection. A large placebo-controlled trial assessing the use of inhaled tobramycin given twice daily on an alternating month basis for 6 months was published in 1999 and shows clear benefit to the use of this regimen as a chronic maintenance therapy for patients colonized with P. aeruginosa. ${ }^{29}$ Pulmonary function was improved and the need for hospitalization was decreased among patients in the inhaled therapy group compared with placebo. Long-term follow-up of patients using inhaled tobramycin has demonstrated efficacy and no significant side effects. ${ }^{52}$ In recently published US guidelines, the chronic use of inhaled tobramycin is recommended for patients aged 6 years and older with $P$. aeruginosa persistently present in cultures of the airways in order to improve lung function and reduce exacerbations. ${ }^{53}$

Nebulized colistin is also commonly used as chronic maintenance treatment for $P$. aeruginosa colonization. One short-term trial of 1 month, with 115 patients included,

Table 2 Antibiotics for the treatment of Pseudomonas aeruginosa infections in cystic fibrosis

\begin{tabular}{|c|c|c|}
\hline Antibiotic & Pediatric dose & Adult dose \\
\hline Oral ciprofloxacin & $10-20 \mathrm{mg} / \mathrm{kg}$ twice a day & 500-750 mg twice a day \\
\hline Tobramycin via inhalation & $300 \mathrm{mg}$ by nebulizer, twice a day ${ }^{\mathrm{a}}$ & $300 \mathrm{mg}$ by nebulizer, twice a day \\
\hline Colistin via inhalation & $75-150 \mathrm{mg}$ by nebulizer, twice a day ${ }^{\mathrm{b}}$ & 75-I50 mg by nebulizer, twice a day \\
\hline Ciprofloxacin & $10 \mathrm{mg} / \mathrm{kg}$ intravenously every $8-12 \mathrm{~h}$ & $400 \mathrm{mg}$ intravenously every $12 \mathrm{~h}$ \\
\hline Ceftazidime & $50-100 \mathrm{mg} / \mathrm{kg}$ intravenously every $8 \mathrm{~h}$ & $2 \mathrm{~g}$ intravenously every $8 \mathrm{~h}$ \\
\hline Cefepime & $50 \mathrm{mg} / \mathrm{kg}$ intravenously every $8 \mathrm{~h}$ & $2 \mathrm{~g}$ intravenously every $8 \mathrm{~h}$ \\
\hline Piperacillin-tazobactam & $90 \mathrm{mg} / \mathrm{kg}$ intravenously every $6 \mathrm{~h}$ & $4.5 \mathrm{~g}$ intravenously every $6-8 \mathrm{~h}$ \\
\hline Aztreonam & $50 \mathrm{mg} / \mathrm{kg}$ intravenously every $8 \mathrm{~h}$ & $2 \mathrm{~g}$ intravenously every $8 \mathrm{~h}$ \\
\hline Imipenem & $15-25 \mathrm{mg} / \mathrm{kg}$ intravenously every $6 \mathrm{~h}$ & $500 \mathrm{mg}$ to I g intravenously every $6 \mathrm{~h}$ \\
\hline Meropenem & $40 \mathrm{mg} / \mathrm{kg}$ intravenously every $8 \mathrm{~h}$ & $\mathrm{I}-2 \mathrm{~g}$ intravenously every $8 \mathrm{~h}$ \\
\hline Doripenem & $10-15 \mathrm{mg} / \mathrm{kg}$ intravenously every $8 \mathrm{~h}$ & $500 \mathrm{mg}$ intravenously every $8 \mathrm{~h}$ \\
\hline Tobramycin & $5-10 \mathrm{mg} / \mathrm{kg}$ intravenously every $24 \mathrm{~h}^{\mathrm{c}}$ & $7 \mathrm{mg} / \mathrm{kg}$ intravenously every $24 \mathrm{~h}^{\mathrm{c}}$ \\
\hline Amikacin & $20-30 \mathrm{mg} / \mathrm{kg}$ intravenously every $24 \mathrm{~h}^{\mathrm{d}}$ & $15-20 \mathrm{mg} / \mathrm{kg}$ intravenously every $24 \mathrm{~h}^{\mathrm{d}}$ \\
\hline Colistin & $1.5-2 \mathrm{mg} / \mathrm{kg}$ intravenously every $8 \mathrm{~h}^{\mathrm{e}}$ & $80-160 \mathrm{mg}$ intravenously every $8 \mathrm{~h}^{\mathrm{f}}$ \\
\hline
\end{tabular}

Notes: an patients $<6$ years, inhaled tobramycin, $80 \mathrm{mg} / \mathrm{I} 2 \mathrm{~h}$; ${ }^{b}$ Dose expressed as milligrams of colistimethate; I mg of colistimethate $=12,500 \mathrm{IU}$. The recommended dose of $75-150 \mathrm{mg} / \mathrm{I} 2 \mathrm{~h}$ is approximately equal to I-2 million IU, twice a day; 'Dosage should be adjusted to serum trough concentration $<\mathrm{I} \mu \mathrm{g} / \mathrm{mL}$; ${ }^{\mathrm{d} D o s a g e}$ should be adjusted to serum trough concentration $<4-5 \mu \mathrm{g} / \mathrm{mL}$; 'Dose expressed as milligrams of colistimethate for patients $<60 \mathrm{~kg}$. Pediatric dose: $18,000-24,000 \mathrm{IU} / \mathrm{kg}$ every $8 \mathrm{~h}$; fDose expressed as milligrams of colistimethate for patients $\geq 60 \mathrm{~kg}$. Adults dose: I-2 million IU every $8 \mathrm{~h}$. 
compared tobramycin and colistin and showed a trend toward greater improvement in $\mathrm{FEV}_{1}$ in the tobramycin group. ${ }^{54}$ However, the use of one agent over the other was not favored in a large meta-analysis. ${ }^{55}$ In this meta-analysis, the incidence of antibiotic resistance with inhaled maintenance therapy was assessed and was of low-frequency occurrence. Nevertheless, patients with highly resistant pathogens detected in sputum cultures may still derive clinical benefits from aerosolized drugs like tobramycin. ${ }^{56}$ This should be due to the pharmacodynamic benefits of inhaled antibiotics with high concentrations attained in the site of infection and low risk of systemic toxicity. ${ }^{57}$ Despite this low risk of systemic toxicity, it has been found that after inhalation of aminoglycosides significant serum drug levels can appear. ${ }^{58-60}$ This fact should be considered in patients with baseline renal failure or in patients receiving other nephrotoxic agents.

Other inhaled agents such as aztreonam, fluoroquinolones, and amikacin are in developmental stages and hold potential as alternative agents for chronic maintenance therapy. ${ }^{61}$ Aztreonam lysine for inhalation solution has been studied in two phase III, randomized, placebo-controlled trials in CF population, and it has shown improvement in respiratory symptoms, pulmonary function, and sputum $P$. aeruginosa density in the treated patients. ${ }^{62,63}$

There is growing interest in evaluating combination therapies to combat $P$. aeruginosa biofilms in the airways of CF patients. Colistin-tobramycin combination has been assessed in biofilm models in vitro and in rat lungs, showing better results than in those cases receiving single antibiotics. In five CF patients, inhaled colistintobramycin was well tolerated and resulted in a mean decrease of $\log (10)$ cfu of $P$. aeruginosa per milliliter of sputum. ${ }^{64}$

Oral antipseudomonal antibiotics could be a comfortable alternative to nebulized therapy for maintenance of long-term treatment. Fluoroquinolones have several characteristics that have made them appealing for oral maintenance therapy: broad spectrum antibacterial activity with excellent bactericidal activity against most $P$. aeruginosa strains, excellent oral absorption, and bioavailability in airway secretions. ${ }^{65}$ Despite ciprofloxacin monotherapy having demonstrated comparable results with intravenous drugs treating mild exacerbations, the emergence of fluoroquinolone-resistant $P$. aeruginosa in treatments for more than 3-4 weeks has been observed. ${ }^{6}$ Thus, prolonged treatment with this antibiotics class is discouraged. ${ }^{6}$

Use of azithromycin, 250 or $500 \mathrm{mg}$ three times weekly, has been recommended for patients with chronic
P. aeruginosa colonization..$^{53,67}$ As a bacteriostatic effect of macrolides against $P$. aeruginosa has not been reported, it has been suggested that an immunomodulating activity is responsible for the observed improvement in CF patients. ${ }^{68}$ This anti-inflammatory effect has been demonstrated in in vitro models and in mice. ${ }^{69,70}$ A recently published meta-analysis demonstrated that the regular use of oral azithromycin shows a small, but significant, improvement in respiratory function at the 1 - and 6-month points. ${ }^{71}$ Some studies also suggest a decrease in the number of exacerbations, ${ }^{67,72,73}$ and only one reported a significant increase in mild adverse events like nausea, diarrhea, and wheezing. ${ }^{67}$

\section{Treatment of patients with exacerbations}

The aim of exacerbations treatment is to restore the baseline lung function present before the onset of respiratory symptoms. In this situation, the antimicrobial therapy is targeted to decrease the bacterial inoculum in the sputum because the eradication of the pathogen is virtually impossible. ${ }^{74,75}$ Moderate and severe exacerbations should be treated with intravenous agents while oral antibiotics (basically ciprofloxacin) are recommended for patients with mild respiratory worsening. ${ }^{34,76}$

The choice of empiric antimicrobial agents is usually based on finding two drugs with differing mechanisms of action which demonstrate in vitro efficacy on conventional drug susceptibility testing of previous sputum cultures and secondly, modifying these agents according to the susceptibility testing of current samples.

Common intravenous regimens generally include the use of an antipseudomonal $\beta$-lactam (piperacillintazobactam, ceftazidime, cefepime, meropenem, imipenem, or aztreonam), combined with an aminoglycoside (amikacin much more widely used than gentamicin or tobramycin). The standard approach to antibiotic treatment of exacerbations due to $P$. aeruginosa has been to use two antipseudomonal drugs to enhance activity and reduce selection of resistant organisms, but this combination therapy has not demonstrated a clear superiority over monotherapy. ${ }^{77}$ Use of a single antibiotic could result in reduced toxicity as well as cost, and these are important issues for patients who will be treated multiple times throughout life. ${ }^{78}$ In a large systematic review, the overall results showed that there was no significant difference between monotherapy and combination therapy in terms of clinical outcome measures, such as lung function and symptoms scores, or in terms of bacteriological outcomes. ${ }^{79}$ However, there was considerable heterogeneity among the eight trials included in the review, and their methodological 
quality was poor. Consequently, adequate meta-analyses for most outcome measures could not be performed.

Standard treatment courses for exacerbations generally last for 14-21 days, but there are no clear guidelines or evidence on the optimum duration. Shorter courses should improve quality of life and compliance, result in reduced incidence of drug reactions, and be less costly. However, this may not be sufficient to clear a chest infection and may result in an early recurrence of an exacerbation. ${ }^{80}$ Treatment can be administered at the hospital setting or at home if clinically and socially possible. Domiciliary intravenous therapy is becoming more common as it reduces the number of hospital admissions, entails fewer investigations, reduces social disruptions, and provides to some patients a better quality of life..$^{81,82}$

An important tool that should complement the antibiotic treatment in respiratory exacerbations is the airway clearance therapy by chest physiotherapy (postural drainage with chest percussion in several anatomic positions to favor gravitational clearance of secretions of all lobes of the lung). ${ }^{6,83}$

\section{Management of infections due to multiple drug resistant $P$. aeruginosa}

Drug resistance is an inevitable problem in CF-related infections linked to the inability to eradicate chronically infecting pathogens and the requirement for repeated courses of antimicrobials during pulmonary exacerbations. In P. aeruginosa, multiple drug resistance (MDR) is defined as resistance to all agents in two or more classes of standard antibiotics, and its prevalence has been reported at $9.6 \%-19.2 \%$ of isolates. ${ }^{84,85}$ MDR $P$. aeruginosa has been associated with increased number of exacerbations, accelerated rate of lung function decline, and increased risk of death. ${ }^{86}$

When $P$. aeruginosa loses susceptibility to the antipseudomonal antibiotics commonly used (fluoroquinolones and $\beta$-lactams), some old and new antibiotics must be considered.

Colistin, a molecule discovered more than 50 years ago, was discontinued because of a high incidence of nephrotoxicity. ${ }^{87}$ This drug has received renewed interest because of its mode of action in disrupting the cytoplasmic membrane of Gram-negative bacteria. ${ }^{88}$ This mechanism protects colistin from crossresistance from other antipseudomonal agents and is unlikely to lead to a rapid selection of new resistance. ${ }^{89}$ The drug displays a concentration-dependent bactericidal activity ${ }^{90}$ and has recently been reintroduced for the management of pulmonary infections in CF patients, either by intravenous route or in the form of an aerosol, with lower rates of toxicity than reported previously. ${ }^{91,92}$
Doripenem is a recently introduced carbapenem that offers potentially enhanced anti-Gram-negative activity relative to previously available drugs of this class but does not expand its spectrum of activity. ${ }^{93} \mathrm{The}_{\mathrm{MIC}}$ of doripenem is generally two-fold to four-fold lower than the corresponding values for meropenem and imipenem and, talking about MDR $P$. aeruginosa strains, this carbapenem remains active against $32 \%$ of $\mathrm{CF}$ isolates nonsusceptible to imipenem and $8.5 \%$ of isolates nonsusceptible to meropenem. ${ }^{94}$ As other $\beta$-lactams, the pharmacodynamic parameter predictive of in vivo efficacy of doripenem is a percentage of the time over required MIC (\%TMIC) (with 30\% generally considered bacteriostatic and $\geq 50 \%$ considered bactericidal). ${ }^{95}$ In modeling studies, using doripenem $500 \mathrm{mg}$ infused over $1 \mathrm{~h}, \%$ TMIC was $45 \%$ for a target of $2 \mathrm{mg} / \mathrm{L}$, but when the infusion was extended to $4 \mathrm{~h}$, this index increased to $68 \% .{ }^{96}$ Using $1 \mathrm{~g}$ of doripenem infused over $4 \mathrm{~h}, \%$ TMIC increased to $81 \%$. According to these results, because of its good tolerability and the absence of significant drug interactions, ${ }^{97}$ this strategy using high doses and extended infusions of doripenem should be assessed in upcoming clinical trials.

Ceftobiprole is a new broad-spectrum cephalosporin with activity against most Gram-positive organisms, including methicillin-resistant Staphylococcus aureus, and similar Gram-negative spectrum to that of cefepime, including $P$. aeruginosa. It is not active against ceftazidime-/cefepimeresistant $P$. aeurginosa, so it does not provide benefits for treating MDR pathogens. ${ }^{98}$

There are methods of testing the susceptibility of bacteria to combinations of antibiotics. Combination antimicrobial susceptibility testing assesses the efficacy of drug combinations including two or three antibiotics in vitro and can often demonstrate antimicrobial efficacy against bacterial isolates even when individual antibiotics have little or no effect. Therefore, choosing antibiotics based on this synergy testing could potentially improve response to treatment in CF patients with acute exacerbation. There is only one randomized controlled trial comparing this strategy with conventional procedures, and its data did not provide evidence that combination susceptibility testing was superior to routine testing. ${ }^{99,100}$

\section{Future therapies}

Most upcoming antimicrobial drugs are new derivatives of existing families with similar mode of action. Therefore, they probably will not solve the problem of emerging multiresistant pathogens. Alternative antimicrobial approaches are gaining more interest to address this problem. Regarding 
prophylactic measures, there have been many approaches in the development of vaccines for the prevention of $P$. aeruginosa infection, but early trials produced disappointing results. ${ }^{101}$ However, a study showed that regular vaccination for a period of 10 years with a polyvalent conjugate vaccine reduced the incidence of chronic infection with $P$. aeruginosa and was associated with better preservation of lung function, particularly in older patients. ${ }^{102}$ With current information, vaccines against $P$. aeruginosa cannot be recommended according to a recently published review, ${ }^{103}$ so further investigations are required.

The main defense mechanisms against Gram-negative bacterial infections are complement-activated killing and complement-mediated opsonophagocytosis. Polysaccharides such as lipopolysaccharides are T cell-independent antigens that trigger the innate immune system via the stimulation of pattern recognition receptors (eg, Toll-like receptor 4). Antibodies induced in response to them are mostly of the immunoglobulin M (IgM) isotype. IgM antibodies have several favorable properties that support their use as therapeutic tools: their pentameric form provides 10 antigen binding sites, they bind antigens with high avidity, and IgM antibodies are very effective complement activators. ${ }^{104}$

Combined treatment with IgM monoclonal antibodies (MAbs) and antibiotics could lead to a more rapid resolution of infections, resulting in shorter stays in intensive care units as well as reductions of morbidity, mortality, and health care costs. Human-obtained MAb against $P$. aeruginosa was assessed in a murine burn wound sepsis model, where full protection of animals against lethal challenges with $P$. aeruginosa was achieved at very low doses. Also, an acute lung infection model using mice showed protection against local respiratory infections.

A study demonstrated the safety of this IgM MAb in healthy volunteers, ${ }^{105}$ and these results warrant further testing of this strategy in infected patients in order to confirm the therapeutic potential of this compound.

Phage therapy is the therapeutic use of bacteriophages to treat pathogenic bacterial infections. Bacteriophages are viruses which specifically and uniquely seek out and destroy bacteria. They do not attack mammalian cells and exist as partners in microbiological ecosystems in the human body and in the environment. Although phage therapy has been known for over 90 years and in spite of the continued use of this technique in eastern Europe, ${ }^{106}$ it has attracted worldwide renewed interest as an alternative or complement to conventional antibiotic therapy due to emergence of multidrug-resistant pathogens. This approach has demonstrated its efficacy in mouse burn wound $P$. aeruginosa infection model ${ }^{107}$ and in mice gut-derived $P$. aeruginosa sepsis model. ${ }^{108}$ The first controlled clinical trial of a therapeutic bacteriophage preparation in humans showed efficacy and safety in chronic otitis due to multidrug-resistant $P$. aeruginosa. ${ }^{109}$

This form of biological therapy has considerable promise, and it should be the subject of for further investigations.

Finally, therapies directed against virulence factors of $P$. aeruginosa (biofilm formation, quorum sensing, flagella, or type III secretion) have been the focus on much recent investigation. These promising translational strategies may lead to the development of adjunctive therapies capable of improving outcomes. ${ }^{110}$

\section{Disclosure}

The authors have no financial interest in this article.

\section{References}

1. Rommens JM, Iannuzzi MC, Kerem B, et al. Identification of the cystic fibrosis gene: chromosome walking and jumping. Science. 1989;245(4922):1059-1065.

2. FitzSimmons SC. The changing epidemiology of cystic fibrosis. J Pediatr. 1993;122(1):1-9.

3. Cystic Fibrosis Foundation Patient Registry: Annual Data Report 2008. Bethesda, MD: Cystic Fibrosis Foundation; 2009.

4. Emerson J, Rosenfeld M, McNamara S, Ramsey B, Gibson RL. Pseudomonas aeruginosa and other predictors of mortality and morbidity in young children with cystic fibrosis. Pediatr Pulmonol. 2002;34(2):91-100.

5. Rosenfeld M, Gibson RL, McNamara S, et al. Early pulmonary infection, inflammation, and clinical outcomes in infants with cystic fibrosis. Pediatr Pulmonol. 2001;32(5):356-366.

6. Gibson RL, Burns JL, Ramsey BW. Pathophysiology and management of pulmonary infections in cystic fibrosis. Am J Respir Crit Care Med. 2003;168(8):918-951.

7. Döring G, Jansen S, Noll H, et al. Distribution and transmission of Pseudomonas aeruginosa and Burkholderia cepacia in a hospital ward. Pediatr Pulmonol. 1996;21(2):90-100.

8. National Nosocomial Infections Surveillance System. National Nosocomial Infections Surveillance (NNIS) System Report, data summary from 1992 Jan through 2004 Jun, issued 2004 Oct. Am J Infect Control. 2004;32(8):470-485.

9. Li Z, Kosorok MR, Farrell PM, et al. Longitudinal development of mucoid Pseudomonas aeruginosa infection and lung disease progression in children with cystic fibrosis. JAMA. 2005;293(5):581-588.

10. Kosorok MR, Jalaluddin M, Farrell PM, et al. Comprehensive analysis of risk factors for acquisition of Pseudomonas aeruginosa in young children with cystic fibrosis. Pediatr Pulmonol. 1998;26(2):81-88.

11. Renders NH, Sijmons MA, van Belkum A, Overbeek SE, Mouton JW, Verbrugh HA. Exchange of Pseudomonas aeruginosa strains among cystic fibrosis siblings. Res Microbiol. 1997;148(5):447-454.

12. Chen SSP, Rudoy R. Pseudomonas infection. Emedicine (Medscape). Available from: http://emedicine.medscape.com/article/970904overview. Updated 2010 Feb 25. Accessed May 202010.

13. Govan JR, Brown AR, Jones AM. Evolving epidemiology of Pseudomonas aeruginosa and the Burkholderia cepacia complex in cystic fibrosis lung infection. Future Microbiol. 2007;2:153-164.

14. Smith EE, Buckley DG, Wu Z, et al. Genetic adaptation by Pseudomonas aeruginosa to the airways of cystic fibrosis patients. Proc Natl Acad Sci U S A. 2006;103(22):8487-8492. 
15. Ramsey DM, Wozniak DJ. Understanding the control of Pseudomonas aeruginosa alginate synthesis and the prospects for management of chronic infections in cystic fibrosis. Mol Microbiol. 2005; 56(2):309-322.

16. Song Z, Wu H, Ciofu O, et al. Pseudomonas aeruginosa alginate is refractory to Th1 immune response and impedes host immune clearance in a mouse model of acute lung infection. $J$ Med Microbiol. 2003;52(Pt 9):731-740.

17. Govan JR, Deretic V. Microbial pathogenesis in cystic fibrosis: mucoid Pseudomonas aeruginosa and Burkholderia cepacia. Microbiol Rev. 1996;60(3):539-574.

18. Poole K, Srikumar R. Multidrug efflux in Pseudomonas aeruginosa: components, mechanisms and clinical significance. Curr Top Med Chem. 2001;1(1):59-71.

19. Poole K, Krebes K, McNally C, Neshat S. Multiple antibiotic resistance in Pseudomonas aeruginosa: evidence for involvement of an efflux operon. J Bacteriol. 1993;175(22):7363-7372.

20. Weldhagen GF, Poirel L, Nordmann P. Ambler class A extendedspectrum beta-lactamases in Pseudomonas aeruginosa: novel developments and clinical impact. Antimicrob Agents Chemother. 2003;47(8):2385-2392.

21. Brasfield D, Hicks G, Soong S, Tiller RE. The chest roentgenogram in cystic fibrosis: a new scoring system. Pediatrics. 1979;63(1): 24-29.

22. Weatherly MR, Palmer CG, Peters ME, et al. Wisconsin cystic fibrosis chest radiograph scoring system. Pediatrics. 1993;91(2): 488-495.

23. Shah RM, Sexauer W, Ostrum BJ, Fiel SB, Friedman AC High-resolution CT in the acute exacerbation of cystic fibrosis: evaluation of acute findings, reversibility of those findings, and clinical correlation. AJR Am J Roentgenol. 1997;169(2):375-380.

24. Helbich TH, Heinz-Peer G, Fleischmann D, et al. Evolution of CT findings in patients with cystic fibrosis. AJR Am J Roentgenol. 1999;173(1):81-88.

25. Santamaria F, Grillo G, Guidi G, et al. Cystic fibrosis: when should highresolution computed tomography of the chest be obtained? Pediatrics. 1998;101(5):908-913.

26. Knudson RJ, Lebowitz MD, Holberg CJ, Burrows B. Changes in the normal maximal expiratory flow-volume curve with growth and aging. Am Rev Respir Dis. 1983;127(6):725-734.

27. Dockery DW, Berkey CS, Ware JH, Speizer FE, Ferris BG Jr. Distribution of forced vital capacity and forced expiratory volume in one second in children 6 to 11 years of age. Am Rev Respir Dis. 1983;128(3):405-412.

28. Kerem E, Reisman J, Corey M, Canny GJ, Levison H. Prediction of mortality in patients with cystic fibrosis. $N$ Engl J Med. 1992;326(18):1187-1191.

29. Ramsey BW, Pepe MS, Quan JM, et al. Intermittent administration of inhaled tobramycin in patients with cystic fibrosis. Cystic Fibrosis Inhaled Tobramycin Study Group. N Engl J Med. 1999;340(1):23-30.

30. Rosenfeld M, Emerson J, Accurso F, et al. Diagnostic accuracy of oropharyngeal cultures in infants and young children with cystic fibrosis. Pediatr Pulmonol. 1999;28(5):321-328.

31. Armstrong DS, Grimwood K, Carlin JB, Carzino R, Olinsky A, Phelan PD. Bronchoalveolar lavage or oropharyngeal cultures to identify lower respiratory pathogens in infants with cystic fibrosis. Pediatr Pulmonol. 1996;21(5):267-275.

32. Henig NR, Tonelli MR, Pier MV, Burns JL, Aitken ML. Sputum induction as a research tool for sampling the airways of subjects with cystic fibrosis. Thorax. 2001;56(4):306-311.

33. Miller MB, Gilligan PH. Laboratory aspects of management of chronic pulmonary infections in patients with cystic fibrosis. J Clin Microbiol. 2003;41(9):4009-4015.

34. Cantón R, Cobos N, de Gracia J, et al. Antimicrobial therapy for pulmonary pathogenic colonisation and infection by Pseudomonas aeruginosa in cystic fibrosis patients. Clin Microbiol Infect. 2005;11(9): 690-703.
35. Burns JL, Saiman L, Whittier S, et al. Comparison of agar diffusion methodologies for antimicrobial susceptibility testing of Pseudomonas aeruginosa isolates from cystic fibrosis patients. J Clin Microbiol. 2000;38(5):1818-1822.

36. Saiman L, Burns JL, Whittier S, Krzewinski J, Marshall SA, Jones RN. Evaluation of reference dilution test methods for antimicrobial susceptibility testing of Pseudomonas aeruginosa strains isolated from patients with cystic fibrosis. J Clin Microbiol. 1999;37(9):2987-2991.

37. Rosenfeld M, Emerson J, Williams-Warren J, et al. Defining a pulmonary exacerbation in cystic fibrosis. J Pediatr. 2001;139(3):359-365.

38. Touw DJ, Vinks AA, Mouton JW, Horrevorts AM. Pharmacokinetic optimisation of antibacterial treatment in patients with cystic fibrosis. Current practice and suggestions for future directions. Clin Pharmacokinet. 1998;35(6):437-459.

39. De Groot R, Smith AL. Antibiotic pharmacokinetics in cystic fibrosis. Differences and clinical significance. Clin Pharmacokinet. 1987;13(4):228-253.

40. Kirkby S, Novak K, McCoy K. Update on antibiotics for infection control in cystic fibrosis. Expert Rev Anti Infect Ther. 2009;7(8):967-980.

41. Bates RD, Nahata MC, Jones JW, et al. Pharmacokinetics and safety of tobramycin after once-daily administration in patients with cystic fibrosis. Chest. 1997;112(5):1208-1213.

42. Smyth A, Tan KH, Hyman-Taylor P, et al. Once versus three-times daily regimens of tobramycin treatment for pulmonary exacerbations of cystic fibrosis - the TOPIC study: a randomised controlled trial. Lancet. 2005;365(9459):573-578.

43. Smyth AR, Bhatt J. Once-daily versus multiple-daily dosing with intravenous aminoglycosides for cystic fibrosis. Cochrane Database Syst Rev. 2010;(1):CD002009.

44. Rosenfeld M, Ramsey BW, Gibson RL. Pseudomonas acquisition in young patients with cystic fibrosis: pathophysiology, diagnosis, and management. Curr Opin Pulm Med. 2003;9(6):492-497.

45. Valerius NH, Koch C, Høiby N. Prevention of chronic Pseudomonas aeruginosa colonisation in cystic fibrosis by early treatment. Lancet. 1991;338(8769):725-726.

46. Frederiksen B, Koch C, Høiby N. Antibiotic treatment of initial colonization with Pseudomonas aeruginosa postpones chronic infection and prevents deterioration of pulmonary function in cystic fibrosis. Pediatr Pulmonol. 1997;23(5):330-335

47. Stuart B, Lin JH, Mogayzel PJ Jr. Early eradication of Pseudomonas aeruginosa in patients with cystic fibrosis. Paediatr Respir Rev. 2010;11(3):177-184.

48. Langton Hewer SC, Smyth AR. Antibiotic strategies for eradicating Pseudomonas aeruginosa in people with cystic fibrosis. Cochrane Database Syst Rev. 2009;(4):CD004197.

49. Gibson RL, Emerson J, McNamara S, et al. Significant microbiological effect of inhaled tobramycin in young children with cystic fibrosis. Am $J$ Respir Crit Care Med. 2003;167(6):841-849.

50. Douglas TA, Brennan S, Gard S, et al. Acquisition and eradication of $P$. aeruginosa in young children with cystic fibrosis. Eur Respir J. 2009;33(2):305-311.

51. Macdonald D, Cuthbertson L, Doherty C, et al. Early Pseudomonas aeruginosa infection in individuals with cystic fibrosis: is susceptibility testing justified? J Antimicrob Chemother. 2010;65(11):2373-2375.

52. Moss RB. Long-term benefits of inhaled tobramycin in adolescent patients with cystic fibrosis. Chest. 2002;121(1):55-63.

53. Flume PA, O'Sullivan BP, Robinson KA, et al. Cystic fibrosis pulmonary guidelines: chronic medications for maintenance of lung health. Am J Respir Crit Care Med. 2007;176(10):957-969.

54. Hodson ME, Gallagher CG, Govan JR. A randomised clinical trial of nebulised tobramycin or colistin in cystic fibrosis. Eur Respir J. 2002;20(3):658-664.

55. Ryan G, Mukhopadhyay S, Singh M. Nebulised anti-pseudomonal antibiotics for cystic fibrosis. Cochrane Database Syst Rev. 2003;3:CD001021.

56. LiPuma JJ. Microbiological and immunologic considerations with aerosolized drug delivery. Chest. 2001;120(3 Suppl):118S-123S. 
57. Lipworth BJ. Pharmacokinetics of inhaled drugs. Br J Clin Pharmacol. 1996;42(6):697-705.

58. Badia JR, Soy D, Adrover M, et al. Disposition of instilled versus nebulized tobramycin and imipenem in ventilated intensive care unit (ICU) patients. J Antimicrob Chemother. 2004;54(2):508-514.

59. Guy EL, Bosomworth M, Denton M, Conway SP, Brownlee KG, Lee TW. Serum tobramycin levels following delivery of tobramycin (Tobi) via eFlow advanced nebuliser in children with cystic fibrosis. J Cyst Fibros. 2010;9(4):292-295.

60. Luyt CE, Clavel M, Guntupalli K, et al. Pharmacokinetics and lung delivery of PDDS-aerosolized amikacin (NKTR-061) in intubated and mechanically ventilated patients with nosocomial pneumonia. Crit Care. 2009;13(6):R200.

61. Sexauer WP, Fiel SB. Aerosolized antibiotics in cystic fibrosis. Semin Respir Crit Care Med. 2003;24(6):717-726.

62. McCoy KS, Quittner AL, Oermann CM, Gibson RL, Retsch-Bogart GZ, Montgomery AB. Inhaled aztreonam lysine for chronic airway Pseudomonas aeruginosa in cystic fibrosis. Am J Respir Crit Care Med. 2008;178(9):921-928.

63. Retsch-Bogart GZ, Quittner AL, Gibson RL, et al. Efficacy and safety of inhaled aztreonam lysine for airway pseudomonas in cystic fibrosis. Chest. 2009;135(5):1223-1232.

64. Herrmann G, Yang L, Wu H, et al. Colistin-tobramycin combinations are superior to monotherapy concerning the killing of biofilm Pseudomonas aeruginosa. J Infect Dis. 2010;202(10):1585-1592.

65. Reed MD, Stern RC, Myers CM, Yamashita TS, Blumer JL. Lack of unique ciprofloxacin pharmacokinetic characteristics in patients with cystic fibrosis. J Clin Pharmacol. 1988;28(8):691-699.

66. Ball P. Emergent resistance to ciprofloxacin amongst Pseudomonas aeruginosa and Staphylococcus aureus: clinical significance and therapeutic approaches. J Antimicrob Chemother. 1990;26 Suppl F: 165-179.

67. Saiman L, Marshall BC, Mayer-Hamblett N, et al. Azithromycin in patients with cystic fibrosis chronically infected with Pseudomonas aeruginosa: a randomized controlled trial. JAMA. 2003;290(13):1749-1756.

68. Peckham DG. Macrolide antibiotics and cystic fibrosis. Thorax. 2002;57(3):189-190.

69. Cigana C, Nicolis E, Pasetto M, Assael BM, Melotti P. Anti-inflammatory effects of azithromycin in cystic fibrosis airway epithelial cells. Biochem Biophys Res Commun. 2006;350(4):977-982.

70. Legssyer R, Huaux F, Lebacq J, et al. Azithromycin reduces spontaneous and induced inflammation in DeltaF508 cystic fibrosis mice. Respir Res. 2006;7:134.

71. Southern KW, Barker PM, Solis A. Macrolide antibiotics for cystic fibrosis. Cochrane Database Syst Rev. 2004;2:CD002203.

72. Southern KW, Barker PM. Azithromycin for cystic fibrosis. Eur Respir J. 2004;24(5):834-838.

73. Equi A, Balfour-Lynn IM, Bush A, Rosenthal M. Long term azithromycin in children with cystic fibrosis: a randomised, placebo-controlled crossover trial. Lancet. 2002;360(9338):978-984.

74. Regelmann WE, Elliott GR, Warwick WJ, Clawson CC. Reduction of sputum Pseudomonas aeruginosa density by antibiotics improves lung function in cystic fibrosis more than do bronchodilators and chest physiotherapy alone. Am Rev Respir Dis. 1990;141(4 Pt 1): 914-921.

75. Ramsey BW. Management of pulmonary disease in patients with cystic fibrosis. N Engl J Med. 1996;335(3):179-188.

76. Smith AL, Doershuk C, Goldmann D, et al. Comparison of a beta-lactam alone versus beta-lactam and an aminoglycoside for pulmonary exacerbation in cystic fibrosis. J Pediatr. 1999;134(4):413-421.

77. Flume PA, Mogayzel PJ Jr, Robinson KA, et al. Cystic fibrosis pulmonary guidelines: treatment of pulmonary exacerbations. Am J Respir Crit Care Med. 2009;180(9):802-808.

78. Al-Aloul M, Miller H, Alapati S, Stockton PA, Ledson MJ, Walshaw MJ. Renal impairment in cystic fibrosis patients due to repeated intravenous aminoglycoside use. Pediatr Pulmonol. 2005;39(1):15-20.
79. Elphick HE, Tan A. Single versus combination intravenous antibiotic therapy for people with cystic fibrosis. Cochrane Database Syst Rev. 2005;2:CD002007.

80. Fernandes B, Plummer A, Wildman M. Duration of intravenous antibiotic therapy in people with cystic fibrosis. Cochrane Database Syst Rev. 2008;2:CD006682.

81. Wolter JM, Bowler SD, Nolan PJ, McCormack JG. Home intravenous therapy in cystic fibrosis: a prospective randomized trial examining clinical, quality of life and cost aspects. Eur Respir $J$. 1997;10(4):896-900.

82. Balaguer A, González de Dios J. Home intravenous antibiotics for cystic fibrosis. Cochrane Database Syst Rev. 2008;3:CD001917.

83. Braggion C, Cappelletti LM, Cornacchia M, Zanolla L, Mastella G. Short-term effects of three chest physiotherapy regimens in patients hospitalized for pulmonary exacerbations of cystic fibrosis: a cross-over randomized study. Pediatr Pulmonol. 1995;19(1):16-22.

84. Lambiase A, Raia V, Del Pezzo M, Sepe A, Carnovale V, Rossano F. Microbiology of airway disease in a cohort of patients with cystic fibrosis. BMC Infect Dis. 2006;6:4.

85. Merlo CA, Boyle MP, Diener-West M, Marshall BC, Goss CH, Lechtzin N. Incidence and risk factors for multiple antibiotic-resistant Pseudomonas aeruginosa in cystic fibrosis. Chest. 2007;132(2): 562-568.

86. Lechtzin N, John M, Irizarry R, Merlo C, Diette GB, Boyle MP. Outcomes of adults with cystic fibrosis infected with antibiotic-resistant Pseudomonas aeruginosa. Respiration. 2006;73(1):27-33.

87. Falagas ME, Kasiakou SK, Tsiodras S, Michalopoulos A. The use of intravenous and aerosolized polymyxins for the treatment of infections in critically ill patients: a review of the recent literature. Clin Med Res. 2006;4(2):138-146.

88. Newton BA. The properties and mode of action of the polymyxins. Bacteriol Rev. 1956;20(1):14-27.

89. Gales AC, Reis AO, Jones RN. Contemporary assessment of antimicrobial susceptibility testing methods for polymyxin B and colistin: review of available interpretative criteria and quality control guidelines. J Clin Microbiol. 2001;39(1):183-190.

90. Li J, Turnidge J, Milne R, Nation RL, Coulthard K. In vitro pharmacodynamic properties of colistin and colistin methanesulfonate against Pseudomonas aeruginosa isolates from patients with cystic fibrosis. Antimicrob Agents Chemother. 2001;45(3):781-785.

91. Falagas ME, Kasiakou SK. Colistin: the revival of polymyxins for the management of multidrug-resistant gram-negative bacterial infections. Clin Infect Dis. 2005;40(9):1333-1341.

92. Falagas ME, Kasiakou SK. Toxicity of polymyxins: a systematic review of the evidence from old and recent studies. Crit Care. 2006;10(1):R27.

93. Parkins MD, Elborn JS. Newer antibacterial agents and their potential role in cystic fibrosis pulmonary exacerbation management. J Antimicrob Chemother. 2010;65(9):1853-1861.

94. Sahm D. In vitro activity of doripenem. Clin Infect Dis. 2009; 49 Suppl 1:S11-S16.

95. Zhanel GG, Wiebe R, Dilay L, et al. Comparative review of the carbapenems. Drugs. 2007;67(7):1027-1052.

96. Cirillo I, Vaccaro N, Turner K, Solanki B, Natarajan J, Redman R. Pharmacokinetics, safety, and tolerability of doripenem after $0.5-$, 1-, and 4-hour infusions in healthy volunteers. J Clin Pharmacol. 2009;49(7):798-806.

97. Chastre J, Wunderink R, Prokocimer P, Lee M, Kaniga K, Friedland I. Efficacy and safety of intravenous infusion of doripenem versus imipenem in ventilator-associated pneumonia: a multicenter, randomized study. Crit Care Med. 2008;36(4):1089-1096.

98. Walkty A, Decorby M, Nichol K, Karlowsky JA, Hoban DJ, Zhanel GG. In vitro activity of ceftobiprole against clinical isolates of Pseudomonas aeruginosa obtained from Canadian intensive care unit (ICU) patients as part of the CAN-ICU study. J Antimicrob Chemother. 2008;62(1):206-208. 
99. Waters V, Ratjen F. Combination antimicrobial susceptibility testing for acute exacerbations in chronic infection of Pseudomonas aeruginosa in cystic fibrosis. Cochrane Database Syst Rev. 2008;3:CD006961.

100. Aaron SD. Antibiotic synergy testing should not be routine for patients with cystic fibrosis who are infected with multiresistant bacterial organisms. Paediatr Respir Rev. 2007;8(3):256-261.

101. Holder IA. Pseudomonas vaccination and immunotherapy: an overview. J Burn Care Rehabil. 2001;22(5):311-320.

102. Lang AB, Rüdeberg A, Schöni MH, Que JU, Fürer E, Schaad UB. Vaccination of cystic fibrosis patients against Pseudomonas aeruginosa reduces the proportion of patients infected and delays time to infection. Pediatr Infect Dis J. 2004;23(6):504-510.

103. Johansen HK, Gøtzsche PC. Vaccines for preventing infection with Pseudomonas aeruginosa in cystic fibrosis. Cochrane Database Syst Rev. 2008;4:CD001399.

104. Spiegelberg HL. Biological role of different antibody classes. Int Arch Allergy Appl Immunol. 1989;90 Suppl 1:22-27.

105. Lazar H, Horn MP, Zuercher AW, et al. Pharmacokinetics and safety profile of the human anti-Pseudomonas aeruginosa serotype 011 immunoglobulin M monoclonal antibody KBPA-101 in healthy volunteers. Antimicrob Agents Chemother. 2009;53(8):3442-3446.
106. Sulakvelidze A, Alavidze Z, Morris JG Jr. Bacteriophage therapy. Antimicrob Agents Chemother. 2001;45(3):649-659.

107. McVay CS, Velásquez M, Fralick JA. Phage therapy of Pseudomonas aeruginosa infection in a mouse burn wound model. Antimicrob Agents Chemother. 2007;51(6):1934-1938.

108. Watanabe R, Matsumoto T, Sano G, et al. Efficacy of bacteriophage therapy against gut-derived sepsis caused by Pseudomonas aeruginosa in mice. Antimicrob Agents Chemother. 2007;51(2): 446-452.

109. Wright A, Hawkins CH, Anggård EE, Harper DR. A controlled clinical trial of a therapeutic bacteriophage preparation in chronic otitis due to antibiotic-resistant Pseudomonas aeruginosa; a preliminary report of efficacy. Clin Otolaryngol. 2009;34(4):349-357.

110. Veesenmeyer JL, Hauser AR, Lisboa T, Rello J. Pseudomonas aeruginosa virulence and therapy: evolving translational strategies. Crit Care Med. 2009;37(5):1777-1786.
Infection and Drug Resistance

\section{Publish your work in this journal}

Infection and Drug Resistance is an international, peer-reviewed openaccess journal that focuses on the optimal treatment of infection (bacterial, fungal and viral) and the development and institution of preventive strategies to minimize the development and spread of resistance. The journal is specifically concerned with the epidemiology of antibiotic

\section{Dovepress}

resistance and the mechanisms of resistance development and diffusion in both hospitals and the community. The manuscript management system is completely online and includes a very quick and fair peerreview system, which is all easy to use. Visit http://www.dovepress.com/ testimonials.php to read real quotes from published authors. 